\title{
Evaluating the Stability of Indigenous Akwadum Soil with Cassava Peel Ash and Quarry Dust
}

\section{Clement Nyamekye, Samuel Anim Ofosu, Alexander Fordjour, Theophilus Ayitey-Adjin}

Department of Civil Engineering, Koforidua Technical University, Koforidua, Ghana

Email: nyamekyeclement@gmail.com

How to cite this paper: Nyamekye, C., Ofosu, S.A., Fordjour, A. and Ayitey-Adjin, T. (2016) Evaluating the Stability of Indigenous Akwadum Soil with Cassava Peel Ash and Quarry Dust. Journal of Geoscience and Environment Protection, 4, 48-55.

http://dx.doi.org/10.4236/gep.2016.412004

Received: August 29, 2016

Accepted: December 5, 2016

Published: December 8, 2016

Copyright $\odot 2016$ by authors and Scientific Research Publishing Inc. This work is licensed under the Creative Commons Attribution International License (CC BY 4.0).

http://creativecommons.org/licenses/by/4.0/

(c) (i) Open Access

\begin{abstract}
Cassava peels are produced as a waste from cassava, which are disposed into landfills. These become an environmental problem; therefore the use of cassava peel ash (CPA) as a soil stabilizer must be encouraged. This study investigates the effects of $\mathrm{CPA}$ and quarry dust (QD) on the engineering properties of Akwadum soil behavior, using compaction test, Atterberg limit, and California bearing ratio (CBR). These properties were compared with those of unstabilized soil (original) and soil stabilized with CPA and QD. The natural soil was obtained from a borrowed pit at Akwadum near Koforidua at an average depth of $0.8 \mathrm{~m}$ which is meant for road works. This soil sample was stabilized with CPA and QD at 5\%,10\% and $20 \%$ respectively. The compaction, California bearing ratio and Atterberg limit test were performed on the stabilized soils to thoroughly evaluate them. The results indicate that increasing the percentage of CPA to the natural soil decreases the maximum dry density at increasing optimum water content. The addition of QD at higher percentage increases the maximum dry density at decreasing optimum water content. The results reveal that both QD and CPA improve the engineering properties of the soil with QD providing better results.
\end{abstract}

\section{Keywords}

Cassava Peel Ash (CPA), Stabilization, Quarry Dust (QD), CBR, Atterberg Limit

\section{Introduction}

It has always been a problem to undertake construction on soft soils such as silt; this has been a major concern in geotechnical engineering. Though the construction on soft soils has been on the increase as a result of economic reasons, its utilization in the developing regions is relatively low. The silt soils have a low undrained shear strength (less than $25 \mathrm{kPa}$ ), extremely high compressibility, poor workability and bearing capac- 
ity [1]. The rapid development and population growth have made it inevitable to have infrastructures in soft soil lands. This has resulted in the need to find solution by improving or increasing the strength of these soft soils [2]. The methods for stabilizing soft soils include chemical and physical. The chemical method is mainly by treating the various soils with additives [1]. Stabilizing soils with different additives for different purposes has become increasingly popular in various literatures [3] [4] [5]. However, the use of cement as a stabilizer has being of great concern for not only their cost but also its negative environmental effect during manufacturing. Lots of researches have been conducted to improve upon the soft soils through modification and stabilization. The effective stabilization of these soils will help increase the strength and also decrease the excessive settlement that occurs when subjected to loads [2].

The rapid increase in population, as well as expansion of industrial facilities has resulted in commercial use of cassava [6]. Cassava peel ash (CPA), a waste from cassava production is one of the most commonly produced waste materials in Ghana. It has strong potential to treat physical and chemical characteristics of soft soils due to its amorphous nature and high silica content [1]. [7] established that CPA contains pozzolanic reactivity when it is calcined at $700^{\circ} \mathrm{C}$ for 90 minutes. It contained more than 70 per cent of combined silica, alumina and ferric oxide when subjected to the above conditions.

It is therefore important to investigate into suitable methods of consuming and using this waste in field of civil engineering (geotechnical), especially in countries like Ghana where agriculture is dominant and compare the results to QD which is widely used and accepted in Ghana. The era of CPA as a stabilizer in geotechnical application has attracted much attention mainly because of its easy accessibility and cheap commercial value. There have been some literatures that investigated the use of CPA as an additional cementitious material to increase the strength of soil in the past year [8]. A review of the literature shows that not much work has been done in Ghana in the past to access the effectiveness of CPA and QD-stabilized soils, particularly soft soils which require high quantities of stabilizer to reach satisfactory results.

This present study investigates the possible use of CPA and QD in stabilizing soft soils under appropriate conditions especially in Ghana. An investigation was conducted on the influence of different percentages of CPA and QD mixtures on the index Atterberg limits, compaction, and California bearing ratio (CBR) of selected Akwadum soil for the above purpose. The Akwadum soil is mostly used as borrow material for road works in parts of the Eastern Region of Ghana.

\section{Materials and Methods}

\subsection{Materials}

Soil: Soil sample was obtained from a borrowed pit at Akwadum in Koforidua meant for road works. The soil samples were obtained at average depths of $0.8 \mathrm{~m}$ to obtain the true representative sample of the soil used for road construction. The sample was spread on different metal pans to facilitate air drying. All the clods and lumps in the 
sample was broken down and well pulverized before running classification test on it.

Cassava Peel Ash: Cassava peel were obtained from restaurant waste dumps, domestic wastes and dump sites of cassava processing locations around Koforidua. The peels were subsequently spread on matting and allowed to properly dry to facilitate proper combustion during burning. The cassava peels were burnt into ashes in a metal drum. The ashes formed were allowed to cool down before sieving through $2.36 \mathrm{~mm}$ BS sieve. The ashes were stored in airtight containers to prevent moisture loss and any form of contamination. Potable water available in the laboratory was used for the study.

Quarry Dust. The quarry dust is the by-product which is formed in the processing of the granite stones which broken downs into the coarse aggregates of different sizes. The QD was obtained from the Kristo Asafo quarry site along the Winneba road.

\subsection{Method}

CBR: The CBR test was carried out on material passing the $2.00 \mathrm{~mm}$ test sieve. With soil particles larger than this, the fraction retained on the $2.00 \mathrm{~mm}$ test sieve was removed and weighted before preparing the test sample. The moisture content of the soil was chosen to represent the design condition for which the test results are required. CBR tests were conducted in compliance with the ASTM D 1883. After preparation of samples, they were sealed by plastic sheets and left to cure in laboratory conditions (23 $\pm 3 \_$C) for 7 days before testing.

Atterberg Limits. The Atterberg limit was used to determine both the liquid limit and plastic limit. In other to determine the physical properties of the soft soil, Liquid limit (LL) and plastic limit (PL) tests were carried out to assess the effects of the CPA and quarry dust. The specimens were cured in a plastic cover for a day, air dried, pulverized, and passed through a $425 \mu \mathrm{m}$ test sieve after mixing. The LL and PL tests were then conducted in line with British standard methods (BS 1377: Part 2) Standard, 1377. The LL and PL tests of the treated specimens were determined after a day as commonly performed in treated soil using chemical binders.

Compaction: Compaction is the densification of soil material by removing air and water from its pore space. There exists a certain amount of moisture that a soil can have where a maximum unit weight is obtained. When the soil is compacted to this state it is referred to as the maximum moisture/unit weight. The Maximum Moisture/Unit Weight is use to determine the Degree of Compaction. Compaction tests were performed according to the modified Proctor test (ASTM D 1557) to determine the maximum dry unit weights $\left(\mathrm{cd}_{(\max )}\right)$ and the optimum moisture contents $\left(\mathrm{w}_{\mathrm{opt}}\right)$ of the untreated and treated soils. Amount of CPA and QD used were 5\%, 10\% and 20\%.

\section{Results and Discussion}

\subsection{The Particle Size Distribution}

The results of the test performed on the natural soil, showed that it was silt or clayey gravel and sand using the AASHTO classification. The silty soil was classified as A-2-7 according to the AASHTO (Table 1), which are mostly rated as subgrades. Figure 1 
shows the particle size distribution curve and Table 1 shows the classification of the natural soil sample.

\subsection{Compaction Characteristics}

The compaction characteristics for the soil were determined. The Proctor standard test according to ASTM D698 (ASTM International, 1998b) was used to obtain the compaction characteristics for the soil. The optimum moisture content (OMC) and maximum dry density (MDD) of the natural soil, quarry dust mixed with natural soil and CPA mixed with natural soil were all determined. Different MDD and OMC values were obtained for Quarry dust mixed with natural soil and CPA mixed with natural soil (Figure 2 and Figure 3).

The natural soil obtained MDD of $2336 \mathrm{~kg} / \mathrm{m}^{3}$ and OMC of 5.4\% (Figure 2 and Figure 3 ). When $5 \%, 10 \%$, and $20 \%$ of quarry dust was added to the natural soil, the MDD values obtained were 2316, 2292 and $2274 \mathrm{~kg} / \mathrm{m}^{3}$ with corresponding OMC of 5.6, 6.8 and $7.1 \%$ respectively (Figure 2 ). When CPA was mixed with the natural soil in the same proportion (Figure 3), the MDD values were 2268, 2290 and $2318 \mathrm{~kg} / \mathrm{m}^{3}$ with

Table 1. Classification of soil sample.

\begin{tabular}{cc}
\hline Description & Classification and rating \\
\hline General classification & Silty or Clayey or gravel or sand \\
Usual type of significant \\
constituent materials \\
General rating as subgrade
\end{tabular}

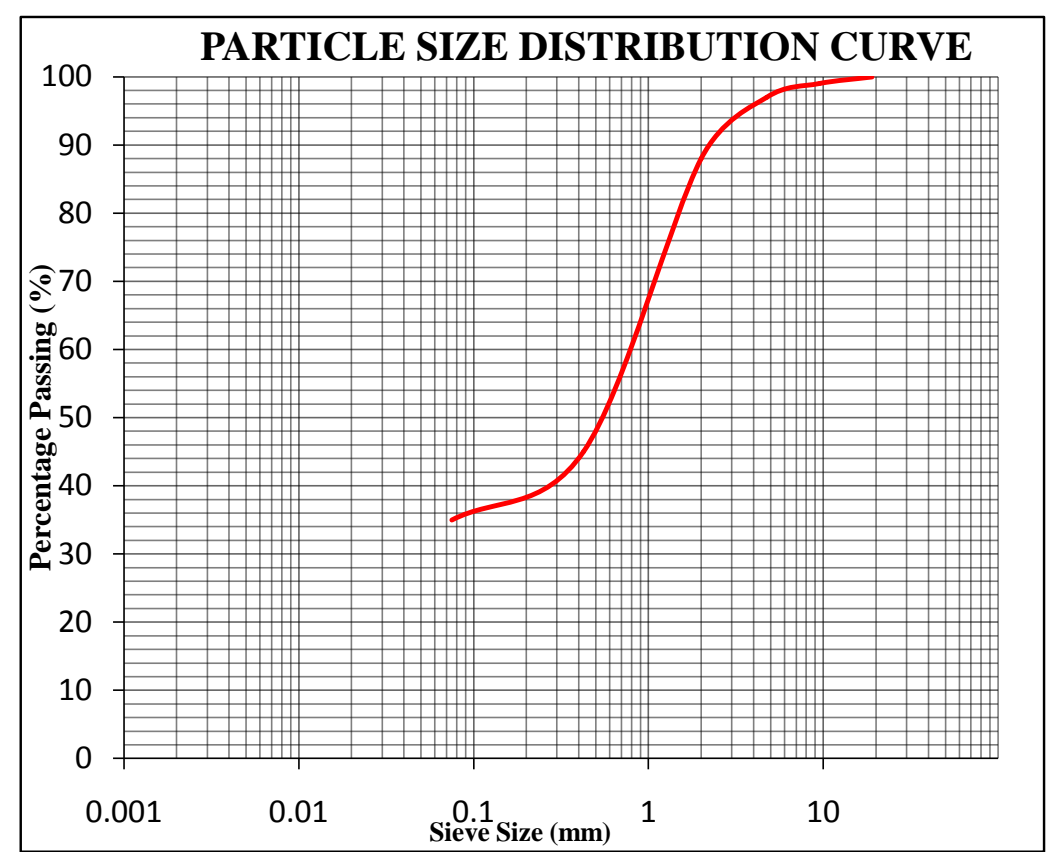

Figure 1. Chart showing particle size distribution curve of the natural soft soil. 


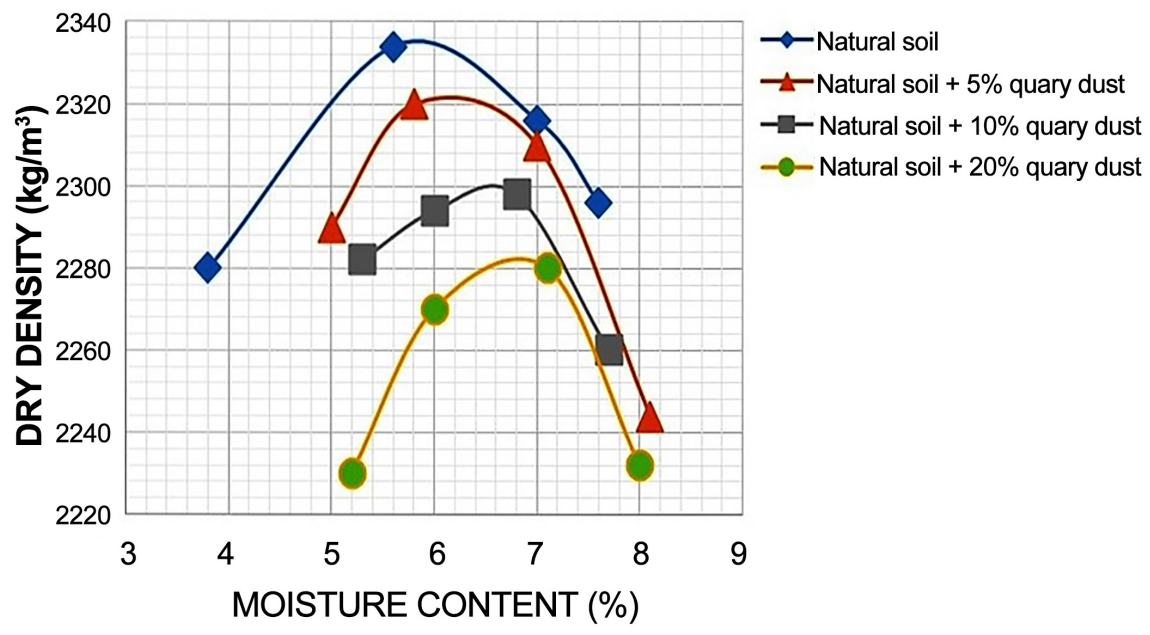

Figure 2. Compaction curve for soil + quarry dust at different variations.

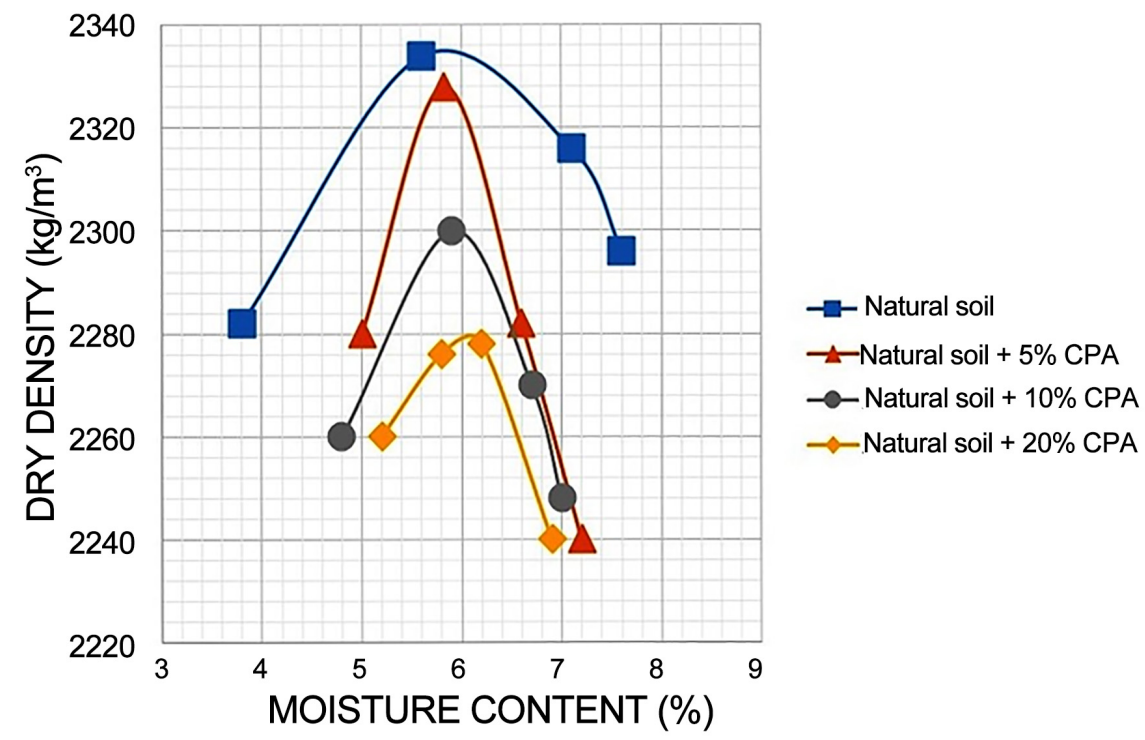

Figure 3. Compaction curve for soil + quarry dust at different variations.

their corresponding values being $6.1 \%, 5.9 \%$ and $5.8 \%$ respectively. Results of the two figures clearly indicate that, the addition of QD to the soil increased the OMC and decreased the MDD while the addition of CPA to the soil caused a decrease in OMC and an increase in MDD. When the QD was replaced with CPA at similar dosages, it was observed that the OMC decreased which might due to the fact that QD has little higher affinity than CPA. The increase in MDD is sign of good improvement in the soil property, while the decrease in OMC depicts an enhancement in the workability of good soil.

The results are in conformity with other researches with works that used other admixtures as a stabilizer [5]. However, there is also slight variation in results which other researches which added cement to the natural soil together with the admixtures [1]. 


\subsection{Atterberg Limit}

The results of the Atterberg limit tests conducted on the natural soil mixed with QD and CPA are shown in Table 2. The addition of QD to the natural soil decreased the plasticity index (PI) of the soil which is similar to the addition of cement to the soil [9]. The PI continuously decreased by increasing the percentage of quarry dust $23.5 \%, 21.6 \%$ and $18.2 \%$ (Table 2). The addition of different proportions of CPA to the soil caused a decrease in both the liquid limit (LL) $47.26 \%, 41.81 \%, 36.90 \%$ and the plastic limit (PL) $20.5 \%, 18.6 \%$ and $16.6 \%$ (Table 2). However, though both LL and PL have a decreasing trend, the values of LL are higher than PL which resulted in a positive PI but in decreasing order (i.e. increasing the percentage of CPA reduced the PI). This causes an improvement in the consistency of the natural soil.

\subsection{California Bearing Ration (CBR)}

The results of the CBR after 96hours of soaking are presented in Table 3. The soaked CBR values for different mixes of natural soil and CPA falls in the range of 17 and 174, with the maximum CBR value of the mix being 174 which was obtained by the mix of natural soil $+20 \%$ CPA. The minimum CBR value for the natural soil + CPA mix was

Table 2. Atterberg limits of soil + various CPA and QD.

\begin{tabular}{cccc}
\hline SAMPLE & \multicolumn{3}{c}{ ATTERBERG LIMITS } \\
NORMAL & LL & PL & PI \\
Soil+ 0.5\% of CPA & 53.69 & 22.20 & 26.50 \\
Soil+ 1\% of CPA & 47.27 & 20.50 & 23.20 \\
Soil+ 2\% of CPA & 41.81 & 18.60 & 20.30 \\
Soil+ 0.5\% of QD & 36.90 & 16.60 & 23.50 \\
Soil+ 1\% of QD & 41.73 & 18.20 & 21.60 \\
Soil+ 2\% Of QD & 39.29 & 17.70 & 18.20 \\
\hline
\end{tabular}

Table 3. CBR test of soil + various CPA and quarry dust.

\begin{tabular}{ccccc}
\hline SAMPLE & \multicolumn{4}{c}{ CBR TEST AFTER 96 HOURS OF SOAKING } \\
\hline NORMAL SOIL & $100 \%$ & $98 \%$ & $95 \%$ & $93 \%$ \\
Soil + $0.5 \%$ of CPA & 57 & 49 & 36 & 28 \\
Soil + 1\% of CPA & 73 & 57 & 33 & 17 \\
Soil + 2\% of CPA & 152 & 93 & 52 & 24 \\
Soil + $0.5 \%$ of QD & 174 & 130 & 50 & 22 \\
Soil + 1\% of QD & 96 & 68 & 39 & 33 \\
Soil + 2\% of QD & 170 & 114 & 59 & 36 \\
\hline
\end{tabular}


17 for natural soil $+5 \%$ CPA (Table 3). Agglomeration of the diverse material of the natural soil and CPA might be responsible for the changes in CBR [10] and the homogenous distribution of CPA in the mixture [11]. For the mixture of natural soil and quarry dust, the CBR values ranges from 33 to 182 (Table 3). The maximum CBR value obtained was 182 , which was a mixture of natural soil $+20 \%$ quarry dust. The minimum value was 33 for the mix of natural soil $+5 \%$ quarry dust. The peak value for each of the mix was obtained at the addition of $20 \%$ of the stabilizer to the natural soil, while the lowest value of CBR was obtained by the addition of $5 \%$ of the stabilizer to the natural soil. The addition of equal proportions of QD and CPA at each instance indicates that $\mathrm{CBR}$ values of $\mathrm{QD}+$ natural soil at all point is always greater than CBR values of $\mathrm{CPA}+$ natural soil. This clearly shows that the addition of CPA has little effects of the engineering properties of the mixture.

\section{Conclusions}

The usage of cassava peel ash (CPA) and quarry dust (QD) in the stabilization of natural soils was investigated. This was geared towards the achievement of green environmental policy and clean technology. The CPA and QD were added to the natural soil at $5 \%, 10 \%$ and $20 \%$ respectively.

The results of the study proved that both QD and CPA are suitable chemical additions to treat the natural soil, but QD is more suitable than CPA. The utilization of CPA as chemical additions would reduce the environmental waste caused by the cassava peels as large amounts would be used in the production of the CPA.

\section{References}

[1] Pourakbar, S., Asadi, A., Huat, B.B.K. and Fasihnikoutalab, M.H. (2015) Stabilization of Clayey Soil Using Ultrafine Palm Oil Fuel Ash (POFA) and Cement. Transportation Geotechnics, 3, 24-35. https://doi.org/10.1016/j.trgeo.2015.01.002

[2] Kolay, P.K. and Aminur, M.R. (2011) Physical and Geotechnical Characteristics of Stabilized and Unstabilized Tropical Peat Soil. World Journal of Engineering, 8, 223-230. https://doi.org/10.1260/1708-5284.8.3.223

[3] Sol-Sánchez, M., Castro, J., Ureña, C.G. and Azañón, J.M. (2016) Stabilisation of Clayey and Marly Soils Using Industrial Wastes: $\mathrm{pH}$ and Laser Granulometry Indicators. Engineering Geology, 200, 10-17. https://doi.org/10.1016/j.enggeo.2015.11.008

[4] Goodarzi, A.R. and Salimi, M. (2015) Stabilization Treatment of a Dispersive Clayey Soil Using Granulated Blast Furnace Slag and Basic Oxygen Furnace Slag. Applied Clay Science, 108, 61-69. https://doi.org/10.1016/j.clay.2015.02.024

[5] Al-Malack, M.H., Abdullah, G.M., Al-Amoudi, O.S.B. and Bukhari, A.A. (2014) Stabilization of Indigenous Saudi Arabian Soils Using Fuel Oil Flyash. Journal of King Saud University - Engineering Sciences, 28, 165-173.

[6] Kleih, U., Phillips, D., Wordey, M.T. and Komlaga, G. (2013) Cassava Market and Value Chain Analysis: Ghana Case Study. C: AVA: Adding Value for Africa. NRI (UK) and FRI (Ghana) Final Report, 66.

[7] Salau, M.A. (2012) Structural Strength Characteristics of Cement-Cassava Peel Ash Blended Concrete. Civil and Environmental Research, 2, 68-78. 
[8] Edeh, J.E., Tyav, S.T. and Osinubi, K.J. (2014) Cassava Peel Ash Stabilized Lateritc Soil as Highway Pavement Material. Pavement Materials, Structures, and Performance, 375-382. https://doi.org/10.1061/9780784413418.037

[9] Okyay, U.S. and Dias, D. (2010) Use of Lime and Cement Treated Soils as Pile Supported Load Transfer Platform. Engineering Geology, 114, 34-44.

https://doi.org/10.1016/j.enggeo.2010.03.008

[10] Hatipoglu, B., Edil, T.B. and Benson, C.H. (2008) Evaluation of Base Prepared from Road Surface Gravel Stabilized with Fly Ash. Geo-Congress, 288-295.

https://doi.org/10.1061/40970(309)36

[11] Li, L., Edil, T.B. and Benson, C.H. (2009) Mechanical Performance of Pavement Geomaterials Stabilized with Fly Ash in Field Applications. Coal Combustion and Gasification Products, 1, 43-49.

\section{Submit or recommend next manuscript to SCIRP and we will provide best service for you:}

Accepting pre-submission inquiries through Email, Facebook, LinkedIn, Twitter, etc.

A wide selection of journals (inclusive of 9 subjects, more than 200 journals)

Providing 24-hour high-quality service

User-friendly online submission system

Fair and swift peer-review system

Efficient typesetting and proofreading procedure

Display of the result of downloads and visits, as well as the number of cited articles

Maximum dissemination of your research work

Submit your manuscript at: http://papersubmission.scirp.org/

Or contact gep@scirp.org 